\title{
Alternative Schemes for the Purification of Bioethanol: A Comparative Study
}

\author{
J Jesús Mendoza-Pedroza and Juan Gabriel Segovia-Hernandez* \\ Departamento de Ingenieria Quimica, Universidad de Guanajuato, México
}

Submission: July 28, 2017; Published: January 22, 2018

*Corresponding author: Juan Gabriel Segovia-Hernandez, Universidad de Guanajuato, Campus Guanajuato, Division de Ciencias Naturales y Exactas, Departamento de Ingenieria Quimica, Noria Alta S/N, Guanajuato, Guanajuato, México 36050, Email: gsegovia@ugtomx.onmicrosoft.com

\begin{abstract}
The increase in the worldwide production of Bioethanol is simultaneous with the development of new technologies to obtain it from waste containing cellulose and hemicelluloses. This situation can give value to the wastes from various industries converting them into raw material for the production of Bioethanol by a fermentation process. Bioethanol yields obtained in the fermentation are usually low, so it must be purified further in separation sequences based on distillation, which usually consume large amounts of energy. In this paper, taking as basis the well known conventional process for purification of Bioethanol, new hybrid arrangements for the purification of ethanol are proposed, based on the combination of liquid - liquid extraction (using n-dodecane as solvent) and extractive distillation (using different entrainers). The results show that these alternative configurations, with the presence of thermal coupling, can generate an alternative purification process to obtain high purity ethanol with low energy consumption, low operating costs and reduction in emissions of greenhouse gases in the process.
\end{abstract}

Keywords: Ethanol; Hybrid processes; Liquid-liquid extraction; Energy savings; Greenhouse gas emissions; Ionic liquids

\section{Introduction}

Bioethanol is obtained by alcoholic fermentation of different organic materials through the action of micro organisms. Production of ethanol from renewable sources lost its importance by mid- $20^{\text {th }}$ century, when it was substituted by the synthetic production of ethanol from petroleum derivatives, which is cheaper. Nevertheless, this synthetic ethanol cannot be used to prepare food, alcoholic beverages nor medicine. Nowadays, with the rise of petroleum prices, fermentative production of ethanol is again competitive and is considered a topic of interest, with the search of cheap raw material as the main focus of research. Such cheap material must substitute the conventional, sugar-containing sources of ethanol. A second topic of interest on ethanol production is the search for a higher efficiency on the fermentation, recovery and purification processes for the produced alcohol [1-3].

The cost for the production of ethanol has an intimate dependence on the costs of the raw material used, and also on its composition and availability. Success for any development plan for crops devoted to the production of ethanol depends strongly of the selection of proper crops, the production methods, and farm location. A production system will have the best opportunities for success if it is established with the lowest raw material costs and is completely integrated so it takes advantage of all the possibilities given by the derivatives [4].

Worldwide, Bioethanol has acquired great value for the possibility of using it as fuel, in mixtures with gasoline or petroleum, and mainly because it is a renewable source of energy. Mixing Bioethanol with the aforementioned products provides of a high quality, cleaner fuel [5-6]. This represents the bioconversion of 2.2 millions of tons of corn or 16 millions of tons of sugarcane (10 and $33 \%$ of the world production, respectively); which are the most used crops for the production of ethanol worldwide [7].

The increase of the production of ethanol takes place at the same time of the development of new technologies that make possible to obtain ethanol from wood chips, solid wastes and other materials containing cellulose and hemicelluloses, giving new value to industrial wastes by converting them into raw material for the obtention of ethanol. Interest for the use of lignocellulosic materials as raw material in transformation processes by microorganisms has become important in the last few decades. The main reasons explaining such interests are [7-10]:

1. Lignocellulosic material is the agro-industrial product with more abundance

2. It is a renewable source of raw material

3. Its three main components (cellulose, hemicelluloses and lignin) have considerable practical applications. For example, cellulose and hemicelluloses are used for the production of ethanol and biomass; while lignin is used as source of fuel or adhesive.

If Bioethanol substitutes gasoline as the main fuel of the transport sector, emissions of greenhouse gases will be reduced 


\section{Recent Advances in Petrochemical Science}

in more than $85 \%$ when the whole fuel cycle is considered [3]. Mixtures of Bioethanol-gasoline with up to $20 \%$ of Bioethanol may be used in the existing internal combustion engines, while the flexible-fuel vehicle may work with conventional gas, Bioethanol of a combination of both.

Bioethanol is nowadays the most important alternative to the use of liquid fossil fuels for the transport sector. In Figure 1 , a general scheme of the production process for Bioethanol is depicted. In this process, Bioethanol is obtained in an aqueous mixture, thus, water must be eliminated to obtain high-purity (more than 99wt\%), anhydrous Bioethanol, since this is the condition in which it can be useful as fuel. Its dehydration is an operation which requires high quantities of energy due to the difficulty for separating the ethanol-water mixture. Broth Bioethanol has usually more than $80 \mathrm{wt} \%$ of water. Thus, high quantities of energy are required for concentrating Bioethanol to a purity of $99.5 \mathrm{wt} \%$. One of the most used techniques for dehydrating Bioethanol is extractive distillation, in which solvents are used to modify the relative volatility of Bioethanol, achieving the desired separation. Other alternatives for Bioethanol dehydration are azeotropic distillation [11], evaporation, adsorption, among others $[12,13]$. Nevertheless, azeotropic distillation may have higher thermal energy requirements than extractive distillation, and evaporation membranes are useful only for low-scale processes. For the adsorption process with molecular sieves, the conditions required in the desorption step has as a consequence high overall equipment costs [11].

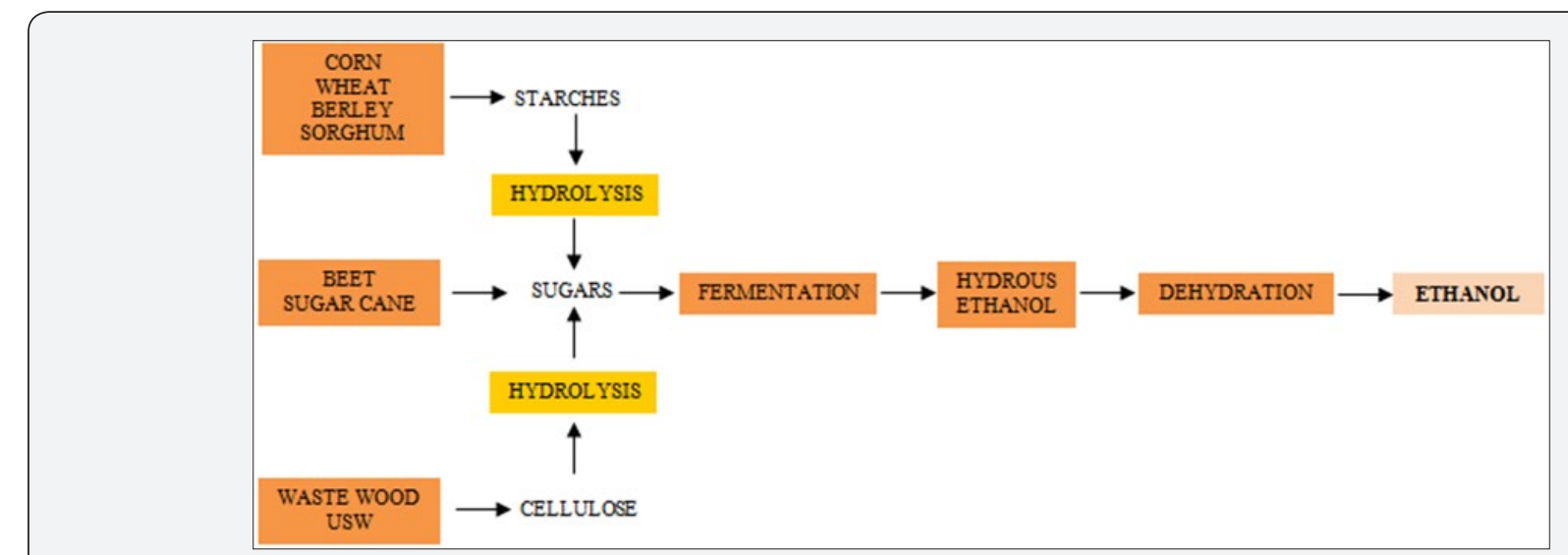

Figure 1: General process for the production of bioethanol.

Nowadays, the main challenge for the dehydration of Bioethanol is reducing as much as possible its thermal energy requirements, operation costs and emission or usage of pollutant substances. Thus, in this work, a study of the performance of different separation agents takes places, aiming to generate alternatives for the extractive distillation of Bioethanol. Different arrangements for the separation of the mixture ethanol/water are analyzed: a process consisting on liquid-liquid extraction and extractive distillation (conventional and with thermal coupling) and a hybrid arrangement with evaporation and extractive distillation. There are only few studies reported for hybrid processes with liquid-liquid extraction and extractive distillation for the dehydration of Bioethanol Avíles-Mártinez et al. [14]. These arrangements are expected to be a good alternative to the conventional Bioethanol purification process, showing lower total annual cost, net energy requirements and greenhouse emissions when compared to the traditional process.

\section{Alternative Hybrid Processes}

The product obtained on the fermentation process contains around $5.12 \mathrm{wt} \%$ of ethanol, thus it is necessary to enrich the mixture for Bioethanol by eliminating most of the water through ordinary distillation until a composition close to the azeotropic is achieved and then purifying by using extractive distillation until purity close to $99.5 \mathrm{wt} \%$ is achieved. This process requires high quantities of energy, causing the process to be expensive.

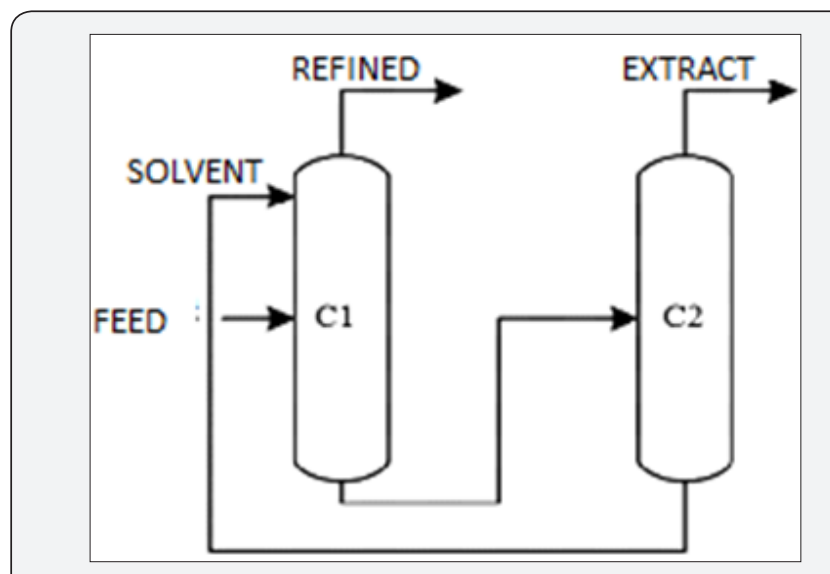

Figure 2 : General scheme of extractive distillation.

Extractive distillation is a separation method for multiple components with similar purposes to those of the azeotropic distillation. When the separation of a binary mixture is difficult or impossible by ordinary methods, a third component, namely a "solvent", is added; this component modifies the relative volatility of the original components, making possible the separation. A typical configuration for extractive distillation is shown in Figure 2. The solvent must have low volatility, avoiding its vaporization in the fractionators. Extractive distillation has many applications: fragrances recovery, alcohols separation from aqueous solutions, 


\section{Recent Advances in Petrochemical Science}

separation of azeotropic mixtures and separation of hydrocarbons with close boiling temperatures. There are different solvents used for ethanol dehydration, with glycerol and ethylene glycol as the most commons at industrial level $[13,15]$.

In the traditional process for Bioethanol purification, it is necessary to enrich the ethanol in the fermentation mixture as a step previous to the extractive distillation. This occurs by eliminating most of the water using ordinary distillation, until a composition close to the zoetrope is reached. By this means, operation costs of the extractive column are reduced. Nevertheless, the conventional column stills consuming high quantities of thermal energy. Recently, the petrochemical enterprise Sasol Ltd. proposed the use of liquid-liquid extraction to separate light alcohols from water using $\mathrm{n}$-dodecane as solvent [16]. N-dodecane is immiscible in water and has a high relative volatility. This first conventional distillation column on the traditional process could be substituted with a liquid-liquid extraction column, generating then a hybrid process with potentially low energy requirements as compared to the traditional process, as proposed previously by
Avilés-Martínez et al. [14]. This alternative is shown in Figure 3a \& $3 b$.

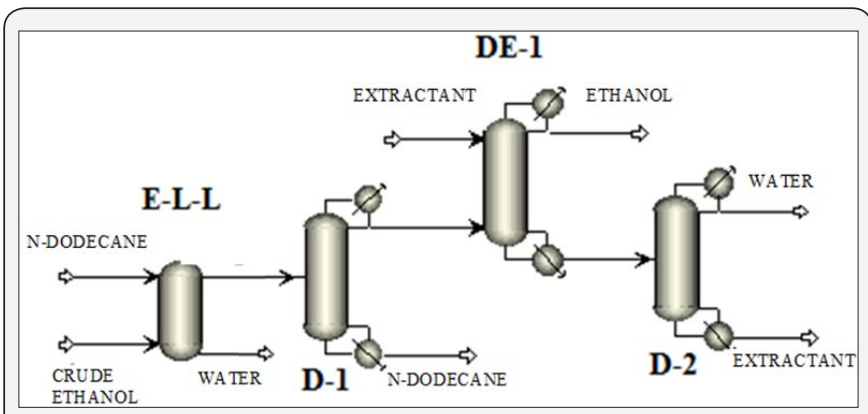

Figure $\mathbf{3}(\mathbf{a}, \mathbf{b})$ : Processes without thermal coupling, (a) Conventional process using extractive distillation for the purification of bioethanol (Process Type I), (b) Hybrid process liquid-liquid extraction/extractive distillation for the purification of bioethanol (Process Type II), (c) Hybrid alternative system liquid-liquid extraction/extractive distillation for the purification of bioethanol (Process Type III), (d) General scheme of the pervaporation process for the purification of bioethanol (Process Type IV).

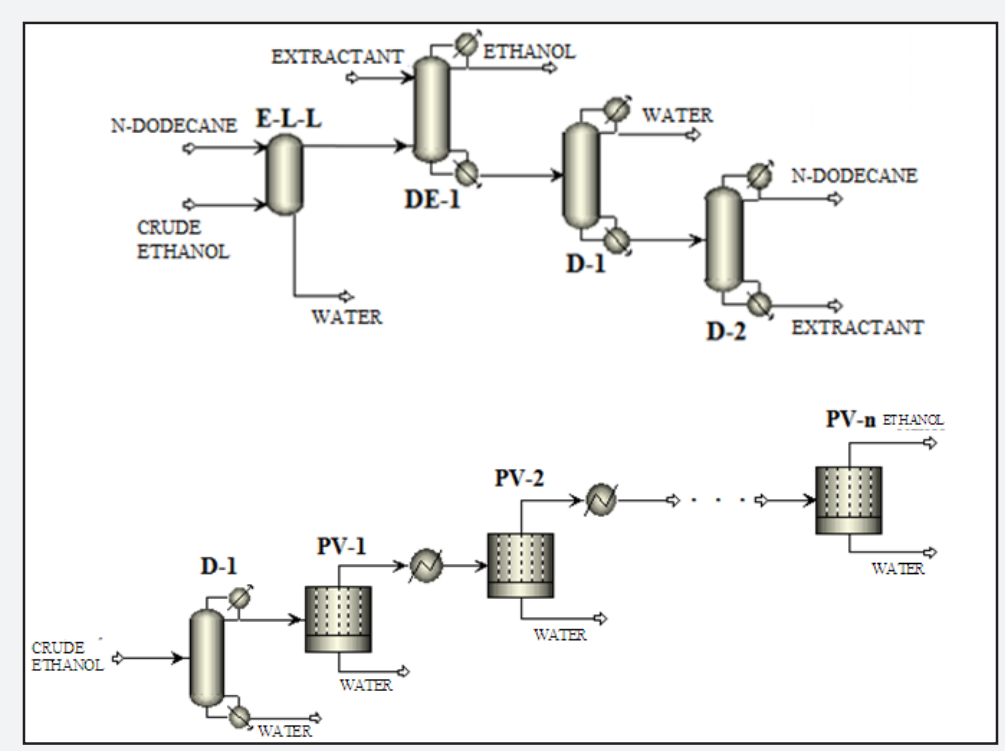

Figure 3(c,d): Processes without thermal coupling, (a) Conventional process using extractive distillation for the purification of bioethanol (Process Type I), (b) Hybrid process liquid-liquid extraction/extractive distillation for the purification of bioethanol (Process Type II), (c) Hybrid alternative system liquid-liquid extraction/extractive distillation for the purification of bioethanol (Process Type III), (d) General scheme of the pervaporation process for the purification of bioethanol (Process Type IV).

Another alternative for obtaining a process with low energy requirements for the purification of Bioethanol is evaporation. Evaporation is a relatively recent separation process in which volatile organic compounds are removed from aqueous mixtures by vaporization through a membrane. The driving force which allows the mass transfer across the membrane is maintained by applying vacuum on the permeate side, keeping the permeate vapor pressure lower than the partial pressure of the feed liquid; this driving force is due to the difference on partial pressures or activities between the liquid feed stream and the permeate vapor $[17,18]$. Partial pressure of water steam is a function of composition and temperature. Feed pressure and temperature must be manipulated so ebullition does not occur. Vacuum on the permeate side must be adequate to ensure there is no condensation on the other side of the membrane, since any condensate film on the membrane pores may inhibit the driving force. To take into account this alternative for the purification of ethanol, the extractive distillation column is substituted by a evaporation train, generating a hybrid distillation-evaporation system (Figure 3c \& 3d).

\section{Cases of Study}

In this section, analyzed purification schemes are presented. All the proposed stage-based separation processes have been 


\section{Recent Advances in Petrochemical Science}

analyzed by using the process simulator Aspen Plus. For all the processes, an initial feed stream with molar flow rate of about $45 \mathrm{kmol} / \mathrm{h}$ and a composition of $90 \mathrm{~mol} \%$ of water and $10 \mathrm{~mol} \%$ of ethanol was used. This stream enters the purification sequence at $1 \mathrm{~atm}$ and $303 \mathrm{~K}$. The cases of study can be classified in four groups: a) Type I, conventional arrangements (Figure 3a \& 3b) Type II, in which liquid-liquid extraction was used in the first step, followed by conventional distillation to recover the first solvent, then extractive distillation and finally conventional distillation for the recovery of the second solvent (Figure $3 \mathrm{~b} \& \mathrm{c}$ ) Type III, in which liquid-liquid extraction was used in the first step, then extractive distillation followed by two conventional distillation columns to recover the two solvents (Figure 3c); and d) Type IV, corresponding to the hybrid distillation-evaporation configuration (Figure 3d).
For the cases II and III, n-dodecane was used as solvent for the liquid-liquid extraction system, while for the extractive distillation column, the effect of three different solvents was studied: glycerol, ethylene glycol, and the ionic liquid 1-butyl-3-methylimidazolium chloride. As a way to reduce thermal energy consumption in the analyzed ethanol purification schemes, the use of thermal coupling has been proposed for those systems on which it is feasible. For the case I, thermal coupling is implemented by a vapor stream leaving the column on which entrainer is purified (D-2), entering the extractive distillation column (Figure 4a). Similarly, in the scheme II a vapor stream leaves the column D-2, introducing it to the column DE-1 (Figure 4b). In Table 1 the main characteristics of the process feed stream are shown. This stream consists on a mixture with $10 \mathrm{~mol} \%$ (22 wt \%) of ethanol at environment pressure and temperature.

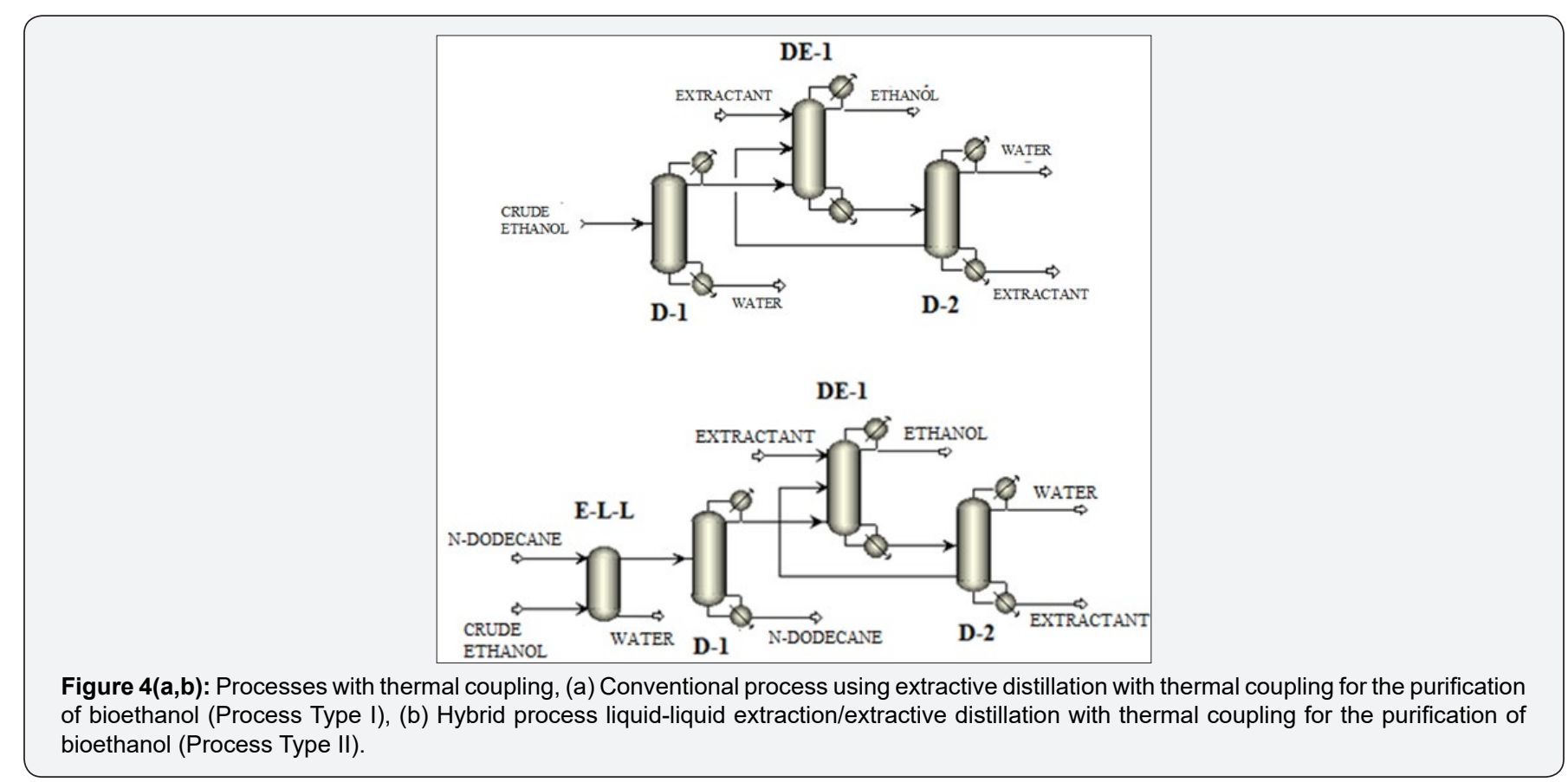

Table 1: Typical mixture ethanol/water leaving a fermenter.

\begin{tabular}{|c|c|}
\hline Temperature $(\mathrm{K})$ & 303.15 \\
\hline Pressure $(\mathrm{kPa})$ & 101.32 \\
\hline Liquid fraction & 1.00 \\
\hline Ethanol mole flow $(\mathrm{kmol} / \mathrm{h})$ & 4.54 \\
\hline Water mole flow $(\mathrm{kmol} / \mathrm{h})$ & 40.82 \\
\hline Ethanol mass flow $(\mathrm{kg} / \mathrm{h})$ & 208.84 \\
\hline Water mass flow $(\mathrm{kg} / \mathrm{h})$ & 734.76 \\
\hline
\end{tabular}

\section{Simulation and Analysis Methodology}

All the processes have been simulated in the commercial process simulator Aspen Plus. Since two liquid phases are formed in most of the analyzed schemes, phase equilibrium is modeled using the thermodynamic model NRTL. This model has been reported as appropriate for the prediction of vapor-liquid equilibrium for the ternary mixture ethanol-water-glycerol [19]. As a way to verify the capacity of $\mathrm{n}$-dodecane to remove water from ethanol, a ternary diagram of the mixture ethanol/water/n-dodecane is shown at 1atm in Figure 5. Two azeotropes can be observed, a binary azeotrope water-ethanol and other binary azeotrope between water and n-dodecane. Nevertheless, that azeotrope is produced at a high purity for water $\left(99.47^{\circ} \mathrm{C}\right.$ of temperature). It can be observed that if $n$-dodecane is used as solvent, water can be obtained almost pure in a single phase, and in a second phase a mixture of ethanol/n-dodecane is obtained. The quantity of water in the second phase will depend of the composition of n-dodecane.

For the simulation of the distillation columns, the block RadFrac has been used with the equilibrium model. In the case of the liquid-liquid extraction columns, the block Extract is used. To simulate the evaporation system, a user subroutine was introduced into the simulator Aspen Plus by using the model User2. The evaporation membrane model presented by Arpornwichanop et al. [20] has been used, considering a polymeric membrane, for 
which values of permeability (Pi) are 0.015 and $0.018 \mathrm{~kg} / \mathrm{cm} 2 \cdot \mathrm{h}$ for ethanol and water, respectively. Permeability data corresponds to a temperature of $298.15 \mathrm{~K}$. To the authors' best knowledge, there is no available information about the variation of the permeability with temperature for this kind of membrane, and thus Pi has been considered constant. The quantity of eliminated water, then, will depend mainly on the membrane area. The model for every membrane has been written in Microsoft Excel and then linked to the simulator Aspen Plus. Input data of the simulator is sent to Excel, where the model computes the output conditions of the evaporation unit, sending this information back to the simulator. The optimization process of the systems involving extractive distillation took place following the strategy shown in Figures 6-7. In Tables 2-5, design parameters of some representative configurations are shown. This data correspond to systems optimized by the aforementioned methodology.

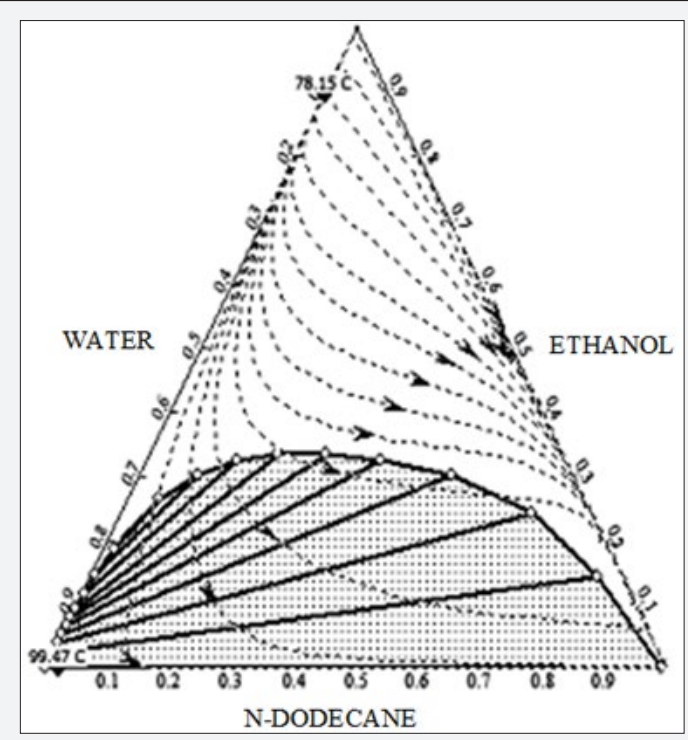

Figure 5 : Ternary diagram of the system etanol/water/ndodecane at $1 \mathrm{~atm}$.

Table 2: Data for conventional distillation/extractive distillation scheme (glycerol).

\begin{tabular}{|c|c|c|c|}
\hline Column & D1 & DE & D2 \\
\hline Number of stages & 20 & 26 & 6 \\
\hline Feeding stage & 10 & 24 & 5 \\
\hline Extractant feedrate(kmol/h) & & 4 & \\
\hline Extractant flowrate(kmol/h) & & 3.18 & \\
\hline Reflux ratio & 6.1902 & 1.134 & 0.3863 \\
\hline Heat duty(BTU/h) & $16,87,110$ & $2,55,904$ & $2,36,953$ \\
\hline $\begin{array}{c}\text { Total heat dutyrequiredper } \\
\text { system(BTU/h) }\end{array}$ & & $19,43,014$ & \\
\hline $\begin{array}{c}\text { Energy provided } \\
\text { bybioethanol(BTU /h) }\end{array}$ & & $52,92,650$ & \\
\hline Equipment cost USD/year & & 58,140 & \\
\hline Utilities costUSD/year & & $6,11,310$ & \\
\hline Total annual cost USD/year & & $6,69,450$ & \\
\hline
\end{tabular}

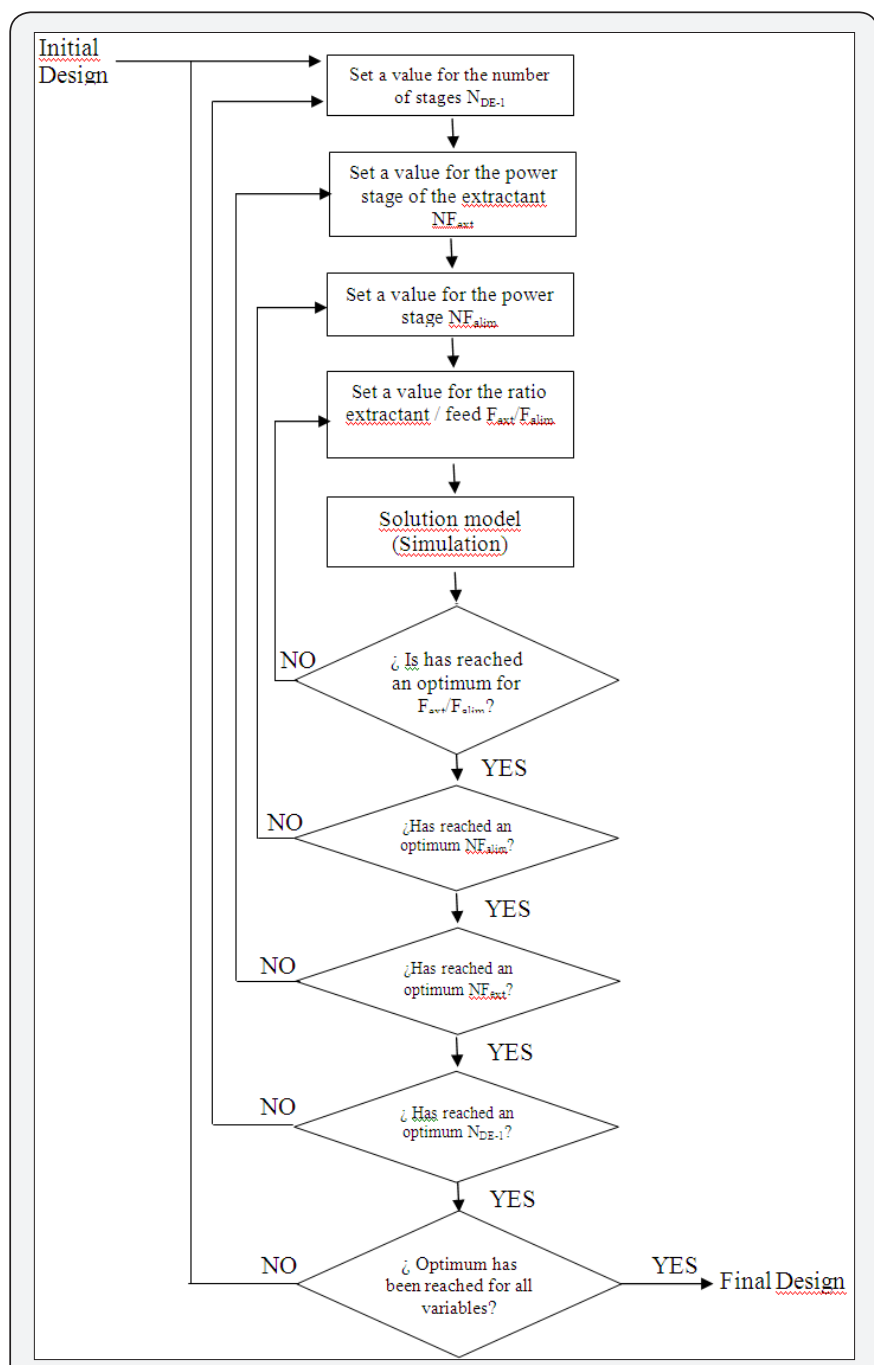

Figure 6 : Optimization methodology for the conventional and hybrid processes for the purification of bioethanol.

Table 3: Data for distillation/extractive distillation scheme with thermal coupling (glycerol).

\begin{tabular}{|c|c|c|c|}
\hline Column & D1 & DE & D2 \\
\hline Number of stages & 69 & 21 & 24 \\
\hline Feeding stage & 66 & $\begin{array}{c}14 \\
\text { (coupling) }\end{array}$ & 3 \\
\hline Extractant feed rate(kmol/h) & & 2 & $\begin{array}{c}36 \\
\text { (coupling) }\end{array}$ \\
\hline Extractantflowrate(kmol/h) & & 7.69 & 1.5 \\
\hline Reflux ratio & 41.1 & 10 & $7,75,396$ \\
\hline Heat duty(BTU/h) & $5,35,573$ & 0 & \\
\hline $\begin{array}{c}\text { Total heat dutyrequiredper } \\
\text { system (BTU/h) }\end{array}$ & & $13,10,968$ & \\
\hline $\begin{array}{c}\text { Energyprovided } \\
\text { bybioethanol(BTU /h) }\end{array}$ & & $51,10,382$ & \\
\hline $\begin{array}{c}\text { Equipment cost USD/year } \\
\text { Utilities costUSD/ year }\end{array}$ & & 52,798 & \\
\hline Total annual cost USD/year & & $5,24,937$ & \\
\hline
\end{tabular}




\section{Recent Advances in Petrochemical Science}

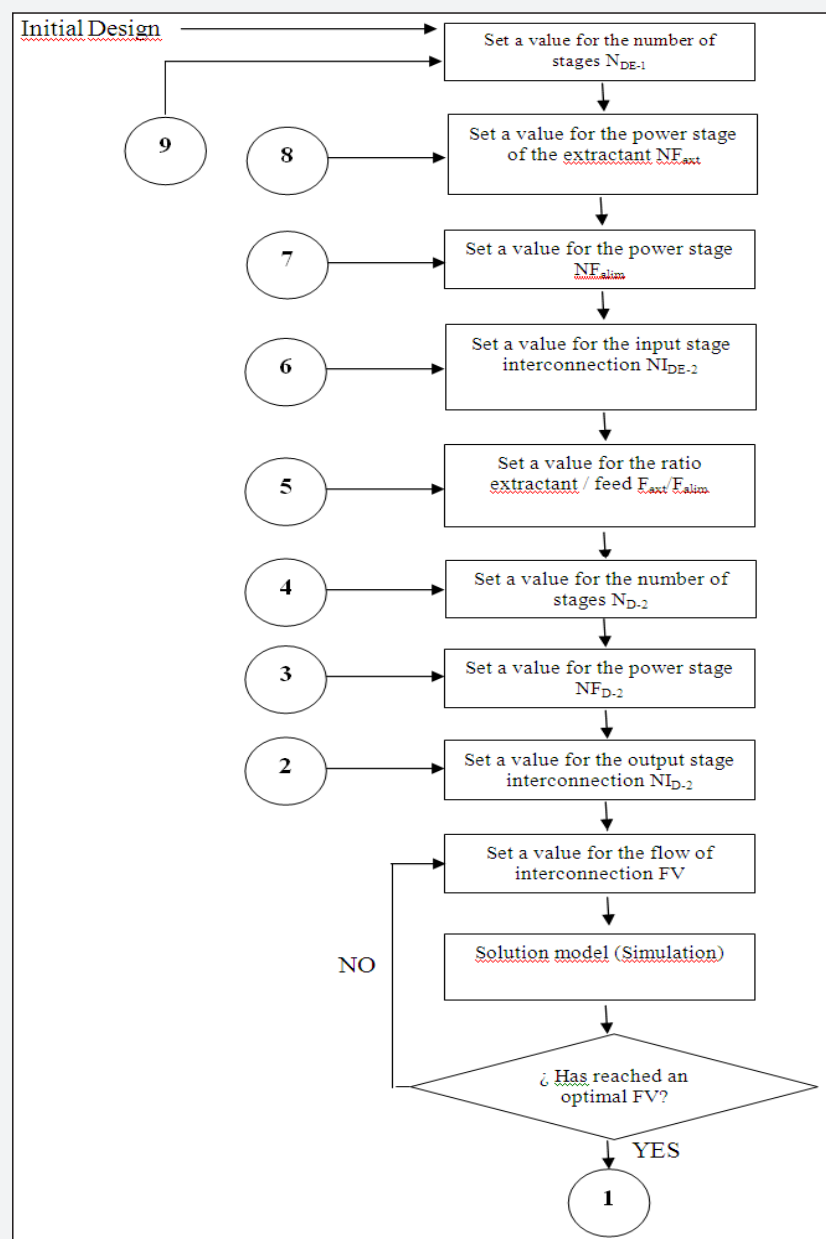

Figure 7a: Optimization methodology for the thermally coupled process for the purification of bioethanol.

Table 4: Data for hybrid system liquid-liquid extraction/extractive distillation (glycerol).

\begin{tabular}{|c|c|c|c|c|}
\hline Column & CE-L-L & D1 & DE & D2 \\
\hline Number of stages & 20 & 16 & 18 & 15 \\
\hline Feeding stage & 20 & 13 & 15 & 7 \\
\hline $\begin{array}{c}\text { Extractant feed rate } \\
\text { (kmol/h) }\end{array}$ & 1 & & 3 & \\
\hline $\begin{array}{c}\text { Extractantflowrate } \\
\text { (kmol/h) }\end{array}$ & 9.98 & 0.023 & 1.45 & 1.99 \\
\hline Reflux ratio & $9,38,344$ & $3,03,317$ & $2,08,530$ \\
\hline $\begin{array}{c}\text { Heat duty(BTU/h) } \\
\text { Total heat } \\
\text { dutyrequiredper } \\
\text { system(BTU/h) }\end{array}$ & $14,50,192$ & & \\
\hline $\begin{array}{c}\text { Energyprovided } \\
\text { bybioethanol(BTU /h) }\end{array}$ & & $52,87,881$ & & \\
\hline $\begin{array}{c}\text { Equipment cost USD/ } \\
\text { year }\end{array}$ & 62,950 & & \\
\hline Utilities costUSD/year & & $2,91,640$ & & \\
\hline $\begin{array}{c}\text { Total annual cost USD/ } \\
\text { year }\end{array}$ & $3,54,590$ & & \\
\hline
\end{tabular}

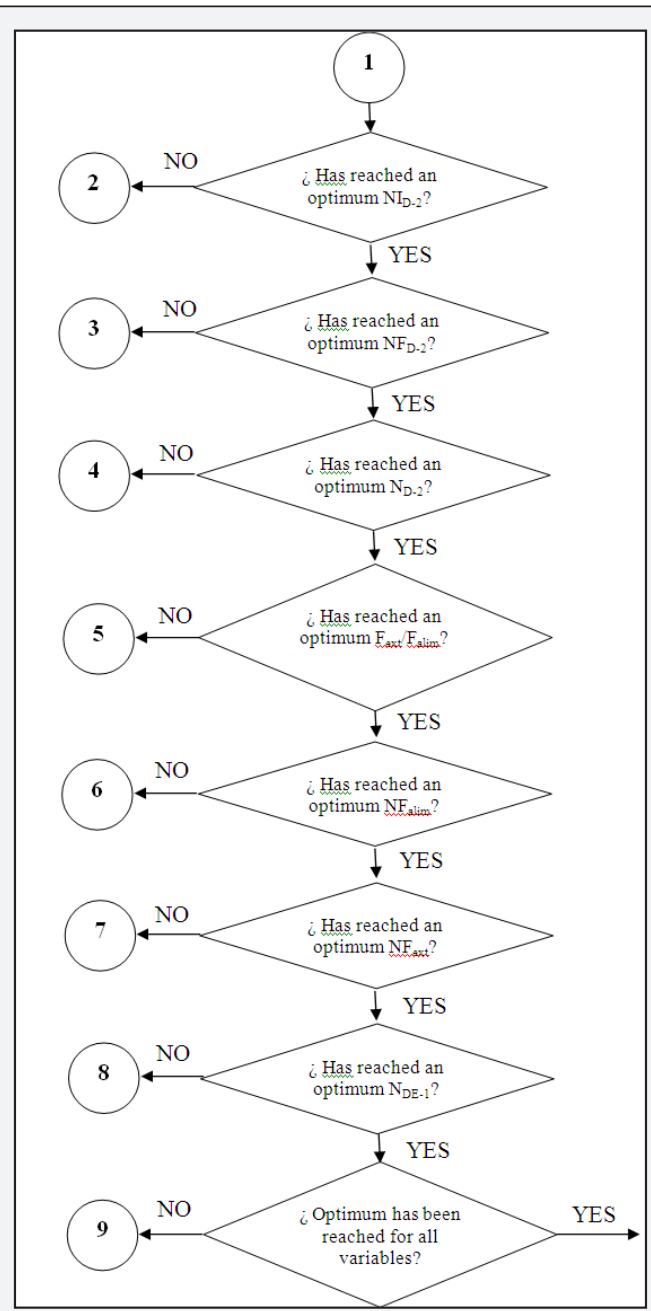

Figure $7 \mathbf{b}$ : Optimization methodology for the thermally coupled process for the purification of bioethanol.

Table 5: Data for hybrid system liquid-liquid extraction/extractive distillation with thermal coupling (glycerol).

\begin{tabular}{|c|c|c|c|c|}
\hline Column & $\begin{array}{c}\text { CE- } \\
\text { L-L }\end{array}$ & D1 & DE & D2 \\
\hline Number of stages & 4 & 9 & 14 & 8 \\
\hline Feeding stage & 4 & 8 & 10 & 4 \\
\hline $\begin{array}{c}\text { Extractant feedrate } \\
\text { (kmol/h) }\end{array}$ & 1 & & 6 & 21 \\
\hline $\begin{array}{c}\text { Extractantflowrate } \\
\text { (kmol/h) }\end{array}$ & 20 & 0.4 & 2 & 0.009 \\
\hline $\begin{array}{c}\text { Reflux ratio } \\
\text { Heat duty(BTU /h) }\end{array}$ & $8,56,276$ & 0 & $2,81,137$ \\
\hline $\begin{array}{c}\text { Total heat dutyrequiredper } \\
\text { system(BTU/h) }\end{array}$ & $11,37,414$ & & \\
\hline $\begin{array}{c}\text { Energyprovided } \\
\text { bybioethanol(BTU /h) }\end{array}$ & & $46,39,883$ & & \\
\hline Equipment cost USD/year & & 55,397 & & \\
\hline Utilities costUSD/ year & & $2,58,191$ & & \\
\hline Total annual cost USD/year & & $3,13,588$ & & \\
\hline
\end{tabular}




\section{Recent Advances in Petrochemical Science}

Once all the optimized designs for the proposed configurations were obtained, three important parameters were determined to establish which design showed the best characteristics to perform the purification of Bioethanol. Those parameters are the external thermal energy consumption, the total annual cost (TAC) and the greenhouse emissions, particularly $\mathrm{CO}_{2}$ emissions. The external thermal energy consumption is taken directly from the results of the simulation as the total heat input for the equipments involved in each process. Total annual costs are calculated taking as a basis Guthrie's method [21] for the capital costs and estimating the utilities requirements from external energy requirements, as follows:

Where CC is the capital costs, OC is the operational costs (associated with the costs for utilities) and $t$ is the time required for recovering the investment. For the calculation of utilities costs, unitary costs shown in Table 6 have been used. To annualize equipment costs, $\mathrm{t}$ has been considered equal to 10 years. To calculate the approximate annual costs of utilities, the hours of operation were estimated at 8500 per year. Greenhouse emissions resulting from the process have been computed according to the procedure of Gadalla et al. [22]. This calculation considers the emissions generated when burning a fuel to obtain the steam which supplies the heat required by the process.

Table 6: Data for calculation of utilities costs [18].

\begin{tabular}{|c|c|c|}
\hline Utility & Temperature (K) & $\begin{array}{c}\text { Unitarycost(USD/ } \\
\text { GJ) }\end{array}$ \\
\hline High pressure steam & 527 & 9.83 \\
\hline $\begin{array}{c}\text { Medium pressure } \\
\text { steam }\end{array}$ & 458 & 8.22 \\
\hline Low pressure steam & 353 & 7.78 \\
\hline Cooling water & 303 & 0.00008 \\
\hline
\end{tabular}

\section{Analysis of Result}

In Figure 8, a comparison between the three kinds of separation schemes is shown, in terms of its total thermal energy requirements. It can be noticed that the Type II schemes (hybrid processes with liquid-liquid extraction, conventional distillation column, extractive distillation, and finally a second conventional distillation column) show the lowest thermal energy requirements. Type I schemes (conventional processes) show the second lowest energy requirements. Configurations of Type III (liquid-liquid extraction, extractive distillation and two conventional distillation columns) are the processes with higher energy demands. It is important to notice three situations which can be observed in Figure 8:

a. In the extractive distillation systems, the use of glycerol as entrainer generates designs with the lowest energy requirements. On the other hand, when the ionic liquid is used as solvent, the obtained designs show the highest thermal energy consumptions. b. The use of thermal couplings on the analyzed systems generated configurations with minimum energy demand.

c. The system using evaporation presents energy consumption similar to that of the thermally coupled systems using ethylene glycol as solvent in the extractive distillation column.

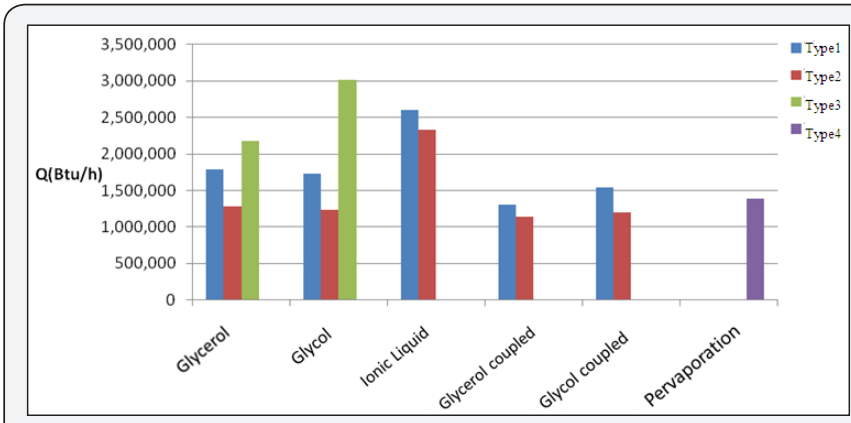

Figure 8 : Energy requirements of the analyzed systems.

In Figure 9, where total annual costs are shown, it can be observed that the Type II systems represent the lowest operational costs (except for the case in which ionic liquid is used as solvent in the extractive distillation column). In particular, Type II configurations with thermal coupling show the minimum operational cost. Type III systems represent the highest total annual costs. Some additional observations can be done:

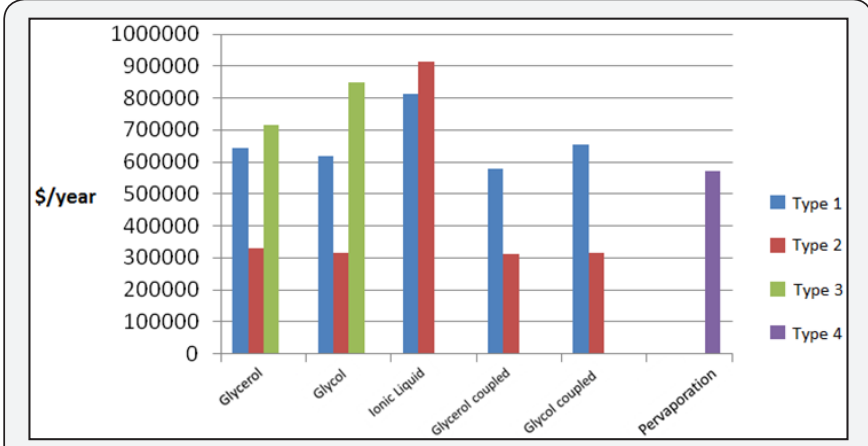

Figure 9 : Total annual cost for the analyzed systems.

a. The systems with glycerol as extraction agent in the extractive distillation column are the configurations with the lowest operational costs.

b. The systems using ionic liquid in the extractive distillation column showed high operation costs.

c. Evaporation systems showed high total annual costs, similar to those obtained for the Type I systems.

In Figure 10, emissions of $\mathrm{CO}_{2}$ are shown for the three proposed kinds of schemes. For this parameter, the best schemes are those of Type II, since they show the lowest calculated $\mathrm{CO}_{2}$ emissions to the atmosphere. This occurs because $\mathrm{CO}_{2}$ emissions are strongly related to the operation of furnaces to provide steam to the process. Thus, since the Type II schemes (particularly those with thermal coupling using glycerol as extraction agent) showed the lowest energy consumption, those schemes have also the 
lowest $\mathrm{CO}_{2}$ emissions. Following this idea, Type III systems and systems using ionic liquid as extraction agent show the highest emissions of greenhouse gases. The system using evaporation shows values for emissions similar to those of the systems using thermal coupling with ethylene glycol as solvent. In general, Type II systems using thermal coupling and glycerol as solvent in the extractive distillation column have the lowest values of thermal energy consumption, total annual cost and greenhouse emissions.

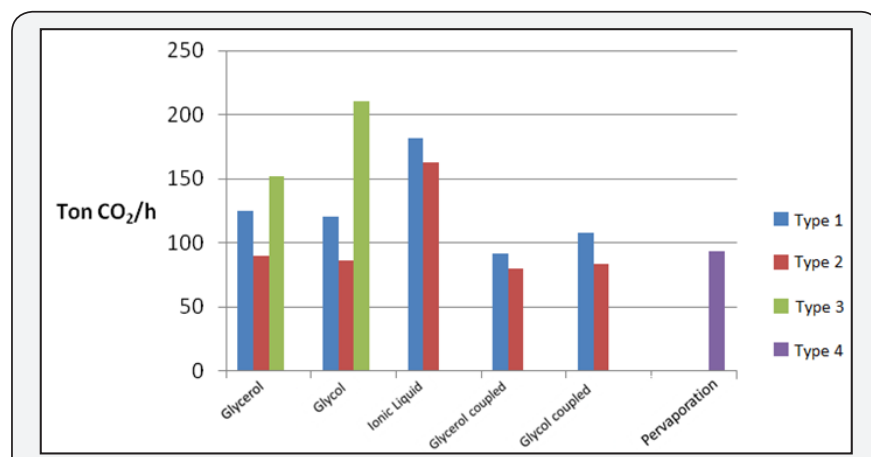

Figure $10: \mathrm{CO}_{2}$ emissions for the analyzed systems.

\section{Conclusion}

In this work, taking as a basis the well-known, conventional Bioethanol purification process, alternative processes have been proposed and analyzed. Such alternative processes involve the use of hybrid systems liquid-liquid extraction/extractive distillation with different configurations. Results show that the Type II schemes have the lowest energy requirements. Those systems consists on using a hybrid system with liquid-liquid extraction, then a conventional distillation column to separate the first solvent, followed by extractive distillation and then conventional distillation to recovery the second solvent. Energy requirements are particularly lower in the Type II system with thermal coupling. The second best alternatives are the Type I systems (conventional processes). Finally, Type III schemes are the worst option in terms of energy demand. It has also been observed that savings in terms of thermal energy consumption, total annual costs, and greenhouse gases emissions are dependent on the kind of solvent used in extractive distillation and the presence of thermal coupling. Using thermal couplings for the studied systems may enhance considerably its energy performance. It can be said that the hybrid system liquid-liquid extraction/extractive distillation is an alternative with considerable savings in energy requirements and total annual costs for the purification of Bioethanol. Particularly, the Type II systems with thermal coupling using glycerol as solvent for extractive distillation are the best option in terms of total annual cost and greenhouse emissions.

\section{Acknowledgement}

The authors acknowledge the support received by CONACyT and Universidad de Guanajuato.

\section{References}

1. Hamelinck CN, Hooijdonk GV, Faaij APC (2005) Biomass Bioenerg. In: Mitchell CP, Overend RP (Eds.), Volume 28: 384.
2. Cardona CA, Sánchez OJ (2006) Energy consumption analysis of integrated flow sheets for production of fuel ethanol from lignocellulosic biomass. Energy 31: 2447-2459.

3. Cardona CA, Sanchez OJ (2007) Fuel ethanol production: process design trends and integration opportunities. Bioresource Technol 98(12): 2415-2457.

4. Ahmetovic E, Martin M, Grossmann IE (2010) Optimization of energy and water consumption in corn-based ethanol plants. Ind Eng Chem Res 49(17): 7972-7982.

5. Singh D, Banat IM, Nigam P, Marchant R (1998) Industrial scale ethanol production using the thermo tolerant yeast Kluyveromyces marxianus IMB3 in an Indian distillery. Biotechnol Lett 20(8): 753-755.

6. Nigam PS, Singh A (2011) Production of liquid biofuels from renewable resources. Prog Energ Combust Sci 37(1): 52-68.

7. Chuck-Hernández C, Pérez-Carrillo E, Heredia-Olea E, Serna-Saldívar SO (2011) Sorgo como un cultivo multifacético para la producción de bioetanol en México: Tecnologías, avances y áreas de oportunidad.Rev Mex Ing Quím 10(3): 529-549.

8. Turhollow AF, Heady EO (1986) Large-scale ethanol production from corn and grain sorghum and improving conversion technology. Energy in Agriculture 5(4): 309-316.

9. Suresh K, Sree NK, Rao LV (1999) Bioresource Technol 68(3): 301-304.

10. Wyman CE (1999) Biomass Ethanol: Technical Progress, Opportunities, and Commercial Challenges. Annu Rev Energy Env 24:189-226.

11. Kiss AA, Suszwalak DJPC (2012) Sep Purif Technol 86: 70.

12. Frolkova AK, Raeva VM (2010) Bioethanol dehydration: State of the art. Theor Found Chem Eng 44(4): 545-556.

13. Gil ID, Uyazán AM, Aguilar JL, Rodríguez G, Caicedo LA, et al. (2008) Separation of ethanol and water by extractive distillation with salt and solvent as entrainer: process simulation. Braz J Chem Eng 25(1): 207215.

14. Avilés-Martínez A, Saucedo-Luna J, Segovia-Hernández JG, Hernández S, Gómez-Castro FI, et al. (2012) Dehydration of bioethanol by hybrid process liquid extraction/extractive distillation. Ind Eng Chem Res 51: 5847-5855.

15. Garcia-Herreros P, Gómez JM, Gil ID, Rodríguez G (2011) Optimization of the design and operation of an extractive distillation system for the production of fuel grade ethanol using glycerol as entrainer. Ind Eng Chem Res 50(7): 3977-3985.

16. Bhownath R, Thesis MS (2008) University of KwaZulu-Natal, Durban, South Africa.

17. Feng X, Huang YM (1997) Liquid separation by membrane pervaporation: A Review. Ind Eng Chem Res 36(4): 1048-1066.

18. Vane LM (2005) J Chem Technol Biotechnol 80(6): 603-721.

19. Gil ID, Gómez JM, Rodríguez G (2012) Comput Chem Eng 39: 129.

20. Arpornwichanop A, Koomsup K, Assabumrungrat S (2008) Hybrid reactive distillation systems for $n$-butyl acetate production from dilute acetic acid. J Ind Eng Chem 14(6): 796-803.

21. Turton R, Bailie RC, Whiting WB, Shaeiwitz JA, Bhattacharyya D, et al. (2012) Analysis synthesis and design of chemical processes. ( $4^{\text {th }}$ edn), Prentice Hall, Michigan, USA.

22. Gadalla MA, Olujic Z, Jansens PJ, Jobson M, Smith R, et al. (2005) Reducing $\mathrm{CO} 2$ emissions and energy consumption of heat-integrated distillation systems. Environ Sci Technol 39(17): 6860-6870. 


\section{Your next submission with Juniper Publishers will reach you the below assets}

- Quality Editorial service

- Swift Peer Review

- Reprints availability

- E-prints Service

- Manuscript Podcast for convenient understanding

- Global attainment for your research

- Manuscript accessibility in different formats

( Pdf, E-pub, Full Text, Audio)

- Unceasing customer service

Track the below URL for one-step submission https://juniperpublishers.com/online-submission.php 